\title{
Gender differences in object location memory: A meta-analysis
}

\author{
DANIEL Voyer \\ University of New Brunswick, Fredericton, New Brunswick, Canada \\ Albert Postma \\ Utrecht University, Utrecht, The Netherlands \\ BRANDY BRAKE \\ University of New Brunswick, Fredericton, New Brunswick, Canada \\ AND \\ JULIANNE IMPERATO-MCGINLEY \\ Weill Medical College of Cornell University, New York, New York
}

\begin{abstract}
The goal of the present study was to quantify the magnitude of gender differences in object location memory tasks. A total of 123 effect sizes $(d)$ drawn from 36 studies were included in a meta-analysis using a hierarchical approach. Object identity memory (37 effect sizes) and object location memory ( 86 effect sizes) tasks were analyzed separately. Object identity memory task showed significant gender differences that were homogeneous and in favor of women. For the object location memory tasks, effect sizes had to be partitioned by age (younger than 13, between 13 and 18, older than 18), object type (common, uncommon, gender neutral, geometric, masculine, feminine), scoring method (accuracy, time, distance), and type of measure (recall, recognition) to achieve homogeneity. Significant gender differences in favor of females were obtained in all clusters above the age of 13, with the exception of feminine, uncommon, and gender-neutral objects. Masculine objects and measures of distance produced significant effects in favor of males. Implications of these results for future work and for theoretical interpretations are discussed.
\end{abstract}

When considering the question of differences in cognitive abilities between men and women, there are specific areas that come to mind quite readily. For a number of years, researchers have been aware that the domains of spatial and mathematical abilities seem especially relevant to the question of cognitive gender differences since they yield marked differences in favor of males (Benbow, 1988; Hedges \& Nowell, 1995; Hyde, Fennema, \& Lamon, 1990; Linn \& Petersen, 1985; Voyer, Voyer, \& Bryden, 1995). Although verbal abilities were long believed to be in favor of women (see, e.g., Maccoby \& Jacklin, 1974), more recent reviews suggest that they are either weakly in favor of women, not significant at all, or even in favor of men, depending on the task considered (Hedges \& Nowell, 1995; Hyde \& Linn, 1988). At the time Maccoby and Jacklin (1974) wrote their landmark book, many believed that spatial, mathematical, and verbal abilities were the only areas where cognitive gender differences occurred.

More recent work, however, suggests that an area of cognitive abilities that was not mentioned by Maccoby and Jacklin (1974) offers potential for emerging gender differences. Specifically, in the early 1990s, a number of researchers reported gender differences in favor of females in tasks requiring memory for the location of objects (see, e.g., Crook, Youngjohn, \& Larrabee, 1990; Sharps, Welton, \& Price, 1993; Silverman \& Eals, 1992). In what is probably the most cited of these studies, Silverman and Eals (1992) developed a task that they claimed reflected a yet unexplored aspect of spatial abilities, namely spatial memory. In this task, participants were presented with a randomly organized array of line drawings on a single piece of paper. Participants studied this array for $1 \mathrm{~min}$, followed by a new piece of paper on which they were required to identify which objects were old (found in the study array) and which ones had been added. This task is labeled as the objects identity memory task hereafter, and it was presented by Silverman and Eals as a measure of memory that is independent of location. Finally, a third array was presented in which some of the objects that had been found in the study array had been moved, whereas others remained where they were (unmoved). Participants were required to identify the moved and unmoved objects. This task is labeled as the conventional object location memory task hereafter, and it was presented as a measure

D.Voyer, voyer@unb.ca 
of object location memory by Silverman and Eals. The authors found that women performed better than men in both tasks. Since then, the results obtained in this initial study (Study 1 of the Silverman \& Eals, 1992, article) have been replicated several times by various researchers with the conventional object location memory task. Note that Crook et al. (1990) reported gender differences in an object location memory task before the publication of Silverman and Eals' report. However, it appears that this finding gained more prominence with the latter authors' work, possibly because they replicated their own results several times in the same paper and framed them within a theoretically broad context.

\section{Interpretation of Gender Differences in Object Location Memory}

The interest that was generated by the Silverman and Eals (1992) study is somewhat puzzling considering that they made a number of questionable methodological, statistical, and conceptual claims. In reality, what likely attracted the interest of many researchers is that Silverman and Eals (1992) called upon evolutionary explanations of cognitive gender differences to account for their findings of gender differences in favor of females on the conventional object location memory task. Specifically, two basic models were contrasted. First, the sexual selection for range-size model was made on the basis of the notion that in polygynous species, sexual selection for homing range occurs, typically favoring males (Gaulin \& Fitzgerald, 1986, 1989). This advantage presumably occurs because good navigation skills are required in males to allow them to look for potential mates or to find resources in order to attract mates. Although this claim has been applied to nonhuman animals, Sherry, Jacobs, and Gaulin (1992) suggested that humans might have a recent evolutionary history of polygyny. Consequently, specific brain structures as well as specific cognitive abilities (in particular, spatial ability) would have shown a sex-specific evolution, resulting in significant differences between men and women. However, Silverman and Eals pointed out that this explanation might be too simple to account for human gender differences. Specifically, this explanation provides a relatively plausible account of gender differences in spatial abilities, but it does not clearly account for gender differences in object location memory. This issue led Silverman and Eals to propose the hunter-gatherer hypothesis as an alternative (Eals \& Silverman, 1994; Silverman \& Eals, 1992). This approach is based on the notion that archeological and paleontological data strongly suggest the presence of task division in males and females such that the former were generally the hunters, whereas the latter were gatherers. Considering that skills that promote successful hunting (abilities to orient oneself in relation to objects and places or across distances, perform mental transformation of objects, etc.) are generally in favor of males in modern humans, Silverman and Eals argued that modern gender differences on spatial tasks can be accounted for by the hunter role held by males. However, these authors also claimed that men outperform women only on those aspects of spatial abilities that are relevant to hunting. Other aspects of spatial abilities relevant to foraging - such as object location memory - should be in favor of women. Of course, their initial work supported this prediction.

Cognitive abilities are not the only aspect of human behavior that can presumably be explained by evolutionary mechanisms. Buller (2005) discussed how the evolutionary psychology paradigm has been used to explain virtually every human behavior. However, he cautioned readers that adaptation occurs continually at the population and individual levels. A correlate of this statement is that the mind is not a static structure that has been preprogrammed to respond in specific ways since the Pleistocene era, as is implied in the hunter-gatherer model. Experiential factors should therefore not be overlooked.

Buller (2005) also made the point that the hypotheses brought forth by evolutionary models are untestable in practice even though they might be testable in principle (see Buller, 2005, p. 88, for elaborations). What Buller means is that we know what kind of evidence is needed to test these hypotheses, and this makes them testable in principle. Unfortunately, we do not have access to the data that are required for this test (such as direct observation of our Pleistocene ancestors), and this makes these hypotheses untestable in practice. This issue is further complicated by the fact that the research methodology for testing the relevant hypotheses uses by definition a quasi-experiment, and this type of design does not allow causal conclusions (Furlong, Lovelace, \& Lovelace, 2000). Another point to consider is that data that are compatible with predictions based on evolutionary models support the plausibility of these models, but do not prove their validity or allow one to reject other models (Lewontin, 1998; but see Ketelaar \& Ellis, 2000, for a contrary view). The argument that was made by Cornell (1997) is especially illuminating in this respect. Specifically, Cornell demonstrated how an evolutionary model could account "plausibly" and with similar arguments for a pattern of gender differences that is the opposite of what we observe today. This demonstration emphasizes Cornell's view that any evolutionary explanation is by definition a post-hoc explanation, not a prediction. In summary, the hunter-gatherer model (among others) appears to provide circular arguments that seem untestable in practice. Although it is possible that the hunter-gatherer model is true, we cannot prove its conclusions. Note also that on the basis of cross-species evidence, Jones, Braithwaite, and Healey (2003) found little support for the hunter-gatherer hypothesis. Despite the problems inherent in an examination of evolutionary explanations and their controversial status, speculation about the theoretical significance of any observed gender difference remains worthwhile.

\section{Alternative Interpretations and Findings}

The initial findings observed by Silverman and Eals (1992) were reported in Study 1 of their article. Study 2 examined whether their findings - initially obtained with drawings - would replicate in a naturalistic setting (which they did). Study 3 was mostly concerned with determining whether gender differences would appear when one 
was informed that he or she had to remember object location (explicit encoding) rather than uninformed of this purpose (incidental encoding). The presence of gender differences in both the explicit and incidental contexts provided a positive answer to this question. Silverman and Eals also implemented manipulations that they claimed demonstrated that gender differences in object location memory could not be accounted for by gender differences in object identity memory. Finally, Study 4 purported to show that gender differences in favor of females on object location memory appear at puberty. Silverman and Eals interpreted their findings as reflecting the influence of changes in hormonal status with puberty on cognitive gender differences. However, one could argue that this conclusion was made on the basis of simple main effects that were computed despite the absence of a significant interaction. These obtained findings thus have a high probability of reflecting a Type I error. Nevertheless, despite relatively weak evidence, Silverman and Eals concluded that their findings strongly supported the hunter-gatherer hypothesis.

Most of the research conducted since the publication of Silverman and Eals's (1992) article aimed at either examining alternative explanations or providing evidence for or against the hunter-gatherer hypothesis. For example, to refute the argument that women might have used verbal labels to produce better location memory scores than men in their task, Eals and Silverman (1994) used uncommon objects that could not be verbally labeled in a variation of their conventional task. Their finding of gender differences in favor of women on this task discounted the verbal mediation interpretation of their earlier findings. However, work conducted by other researchers provided mixed evidence concerning the generalizability of gender differences in object location memory. In one such study, James and Kimura (1997) noted that women were significantly better than men at tasks involving object exchanges (when objects change location with each other, as in the conventional object location memory task), but not tasks involving objects that were shifted from their original location to occupy those that were previously unoccupied. Arguably, the former predominantly assesses a form of topological memory, whereas the latter measures a more precise aspect of location memory, possibly calling on a coordinate component. In contrast, Dabbs, Chang, Strong, and Milun (1998) and Epting and Overman (1998) did not observe any difference between men and women in object location memory. Finally, in three recent studies, Postma and colleagues (Postma, Izendoorn, \& De Haan, 1998; Postma, Jager, Kessels, Koppeschaar, \& van Honk, 2004; Postma, Winkel, Tuiten, \& van Honk, 1999) reported a male advantage rather than a female advantage for object location memory.

Considering the focus of research on supporting or refuting the hunter-gatherer hypothesis, one can plausibly argue that the consideration of this broad picture has taken researchers away from an examination of task components that might account for the gender differences. Specifically, researchers might be focusing so closely on the broad ex- planation that they are disregarding other, more parsimonious accounts of the gender differences.

As a starting point, recent research suggests that object location memory may comprise three major components: (1) object processing, (2) spatial-location processing, and (3) binding objects to locations (Postma et al., 2004). A simplified account of these components within the context of the conventional object location memory task suggests that they are clearly involved and might affect the observed gender differences. Specifically, object processing requires one to recognize the objects, thereby encoding their identity. This aspect would be tapped by the object identity memory task. Spatial location processing can proceed both by means of exact coordinate location codes and by relative, categorical, or topological codes. The processing of spatial location is not necessary to object identity memory. However, it is required to achieve the third step, when the object is bound to its location. Essentially, this requirement suggests that the last operation in object location memory is the establishment of a connection between object identity and location. This discussion supports the notion that object identity memory and object location memory involve interdependent but separate processes. From this perspective, we likely identify an object first, locate it, and then bind it to a location. This process raises the possibility that gender differences in object location memory might relate to gender differences in object identity memory. The present study examined this possibility by investigating gender differences in object identity and location separately. Consideration of the magnitude of the effect on each measure should provide some clues concerning possible precedence effects.

The above findings and discussion suggest that gender differences in object location memory might not be as clear-cut as Silverman and Eals (1992) claimed. Accordingly, in light of the apparent contradiction in findings relevant to gender differences in object location memory, the goal of the present study was to give a more conclusive overview of the existence of gender differences in this cognitive domain as well as in the conditions under which they emerge. As was already pointed out, the literature on gender differences in object location memory appears quite diffuse. The various relevant studies will not be discussed at length because they form part of the database presented later. However, elaborations on possible reasons for contradictory results are likely to provide clues concerning clusters of homogeneous effect sizes that might emerge through meta-analysis. The first class of reasons is methodological and statistical, including factors such as sample size, the file drawer problem (which will be discussed shortly), scoring procedure, the type of objects used, the setting of the task, encoding context, and age of the sample. The second is theoretically based, comprising the exact cognitive subcomponents underlying object location memory.

Methodological and statistical factors accounting for mixed results. Starting with the first class, an important methodological issue concerns limitations in group size. In general, men and women overlap consider- 
ably in cognitive performance (see, e.g., Kail, Carter, \& Pellegrino, 1979). Hence, relatively large group sizes are needed to obtain significant statistical differences. When comparing homogeneous groups (e.g., college students), significant effects might be obtained with only 20 participants in each group, but clearly this depends on the sensitivity of the test. One goal of the present meta-analysis was to minimize this problem by combining several samples of various sizes while increasing the importance of results obtained with large sample studies through the use of effect sizes that were weighted as a function of sample size (Hedges \& Becker, 1986).

A second methodological concern relates to the wellknown file drawer problem (Rosenthal, 1979). Studies yielding no effects or unexpected effects may not be published, thereby obscuring the true pattern of gender differences and the validity of the meta-analytic approach. One can plausibly speculate that since the dominant view regarding gender differences in object location memory currently favors women, several studies showing no gender difference or a male advantage may not have been published and have vanished in file drawers, whereas those showing the expected effect were published. One of the advantages a meta-analysis offers is that it allows an estimate of how many studies with nonsignificant or contradictory findings would be required to offset the significance of a given effect size. Thus, the present study examined the resistance of gender differences in object location memory to the file drawer problem. In addition, efforts were expended to include unpublished studies in the analysis.

Another methodological aspect that deserves consideration concerns the scoring procedure used in a specific experiment. Voyer et al. (1995) reported that on a number of tests, the scoring procedure had a significant effect on the magnitude of gender differences in spatial abilities. It is a fact that various scoring techniques have been used in object location memory tasks. Specifically, the typical score used by Silverman and Eals (1992) is accuracy of response (i.e., the object is either in the correct location or not). However, others (e.g., Postma et al., 2004) have used the distance between actual object location and the placement made by participants as a score. Completion time has also been used as the measure of performance (Tottenham, Saucier, Elias, \& Gutwin, 2003). Such variations in the scoring procedure are likely to affect the results of studies using object location memory tasks as they do for spatial tasks. This possibility also has theoretical implications (see below), and as such it was taken into account here. In addition, recent reports suggest that men show a greater propensity to guess than do women (Voyer, Rodgers, \& McCormick, 2004; Voyer \& Saunders, 2004). It is thus possible that test scores that include a correction for guessing could produce a different magnitude of gender differences in object location memory, as was observed by Voyer et al. (1995) for spatial tasks. In the object location memory task, a correction for guessing is typically applied by subtracting the number of objects incorrectly identified as moved and unmoved from the number that are correctly identified as moved and unmoved. The present analysis will thus examine whether this type of correction affects the magnitude of gender differences in the task.

The use of uncommon objects by Eals and Silverman (1994) was mentioned earlier as part of their attempt to examine the verbal mediation explanation of their previous findings. However, others have speculated that the type of objects that are used might influence the magnitude of gender differences in object location memory through their relevance to the participants. For example, Cherney and Ryalls (1999) speculated that their participants would be more likely to remember the location of genderrelevant toys than gender-irrelevant toys. Their finding confirmed this prediction while also demonstrating that gender relevance nullified overall gender differences in favor of females in object location memory. Findings of this type suggest that it is very important to consider the type of object used in the studies retrieved for the present analysis.

Additional factors that require consideration relate to the ecological validity of the tasks used. Specifically, considering that the hunter-gatherer interpretation of gender differences is based on the notion that the female advantage arose as a result of a long evolutionary process that occurred in the natural environment, one can plausibly expect that gender differences should be found in studies that recreate this natural setting as well as in those where artificial conditions are used. Thus, the females' advantage over males should be found when the task involves a naturalistic setting as well as when drawings of objects or computer tasks are used. The hunter-gatherer hypothesis also leads to the prediction that women should excel particularly under incidental learning conditions, because these conditions are the most closely connected to their original gatherer role (Silverman \& Eals, 1992). That is, it might be a natural automatic tendency of gatherers to store locations of relevant items into memory even when there is no direct usage for those items at present. Eals and Silverman's (1994) finding that women had an advantage when participants were not informed that they had to remember uncommon object location (incidental encoding), but that men had an advantage when they were forewarned (explicit encoding) supported this point. On the basis of their statement that "for unfamiliar objects, the female advantage occurs solely for location memory in incidental learning conditions" (Eals \& Silverman, 1994, p. 103), these authors concluded that females might have evolved an attentional style that is more inclusive of the environment than that of males. This might lead one to expect that gender differences in object location memory should be more pronounced under incidental rather than explicit encoding conditions, at least for uncommon objects. This question will be examined in the present analysis.

Another methodological factor that requires consideration is the type of measure used. For example, Rahman, Wilson, and Abrahams (2003) reported gender differences in favor of females in object recall, but not in recognition. Considering that the conventional object location memory task is always administered as a recognition measure, this could mask gender differences of even larger magnitude. Accordingly, the present study took into account the 
type of measure in retrieving studies for inclusion in the meta-analysis.

Age of the sample is a variable that should not be overlooked when investigating gender differences in cognitive abilities. In fact, Linn and Petersen (1985) and Voyer et al. (1995) reported age effects in the examination of spatial abilities. Linn and Petersen proposed a categorical division of age groups: under 13,13 to 18 , or over 18 , and this categorization was utilized by Voyer et al. (1995). In both meta-analyses, the data suggested that gender differences emerge at puberty or around cognitive events such as the emergence of concrete-operational thoughts, around the age of 7 (Piaget, 1952). Thus, the age factor is likely to provide important insights concerning the possible role of neuroendocrinological and cognitive mechanisms, as was suggested by Silverman and Eals (1992).

Conceptual and theoretical factors accounting for mixed results. The second class of reasons that might account for mixed findings regarding gender differences in object location memory relates to the notion that object location memory is a multicomponent process. The importance of this point lies in the fact that various subcomponents might be differentially sensitive to gender differences. A consideration of the levels of spatial information required in object location memory suggests that spatial location processing entails two forms that are distinguished by the grain of the spatial code. One form consists of exact metric coding of the position of an object. Kosslyn et al. (1989) labeled this component as reflecting coordinate spatial coding. Alternatively, we may use a more global, coarse, or relative code to describe an object's position. Such relative or categorical spatial codes define an equivalent class of spatial locations, which captures the invariant or abstract aspects of an item's location (Jager \& Postma, 2003). Both the categorical and coordinate components are likely to be useful when one attempts to locate an object. For example, when looking for our eyeglasses, a categorical code ("the eyeglasses are on the table") or an exact position code ("the eyeglasses are $35 \mathrm{~mm}$ away from the upper left corner of the table") may be used. The former suffices for finding and remembering the object's location. The latter is necessary when we want to pick it up.

The distinction between coordinate and categorical spatial coding has been applied to the issue of gender differences in spatial processing as well. Some have suggested than men are better than women in coordinate spatial relation processing, whereas gender differences favor women for categorical relation processing. While the evidence for these expectations remains weak in the field of spatial perception (Hellige, et al., 1994; Hellige \& Mitchimata, 1989; Jager \& Postma, 2003; Rybash \& Hoyer, 1992), results from spatial memory studies appear more promising (Alexander, Packard, \& Peterson, 2002; Postma et al., 2004). A simple methodological approach to distinguish these two types of spatial coding in object location memory is to consider the distance between actual object location and its placement by participants in a recall task as a reflection of the coordinate component. In contrast, a simple measure of accuracy where participants indicate moved and unmoved objects would reflect a categorical component. Although it is clear from the discussion above that the categorical-coordinate distinction is not new, it would appear that the operationalization of accuracy and distance measures in object location memory to reflect this underlying distinction is novel. In addition, this operationalization allows clear predictions concerning the outcome of a meta-analysis examining gender difference in clusters of studies that differ in scoring procedure. Specifically, a distance measure should produce gender differences in favor of males, whereas an accuracy measure should favor females.

In summary, the present study examined the magnitude of gender differences in object location memory. As was the case in similar efforts in the areas of spatial, verbal, and mathematical abilities, partitioning of effect sizes in homogeneous clusters was expected to contribute to an identification of factors that are critical to gender differences in object location memory. A systematic examination of variables relevant to a test of the hunter-gatherer hypothesis as well as alternative explanations are thus expected to provide evidence concerning the conditions under which gender differences in object location memory are observed.

\section{METHOD}

\section{Selection Criteria for Inclusion in the Meta-Analysis}

The present meta-analysis includes published and unpublished studies presenting results that were obtained with different versions of the object location memory task. In many of the studies, the object identity memory task was also included as a distractor or control task. Considering that this measure is clearly different from object location memory (Silverman \& Eals, 1992) and that the present analysis focuses on object location memory, object identity memory data were analyzed separately from object location memory data. Note also that studies that used only an object identity memory task were not included in the analysis.

PsycInfo searches were conducted as a starting point for the retrieval of studies, and the reference list of retrieved papers was searched for more relevant studies. Researchers who had previously published in this area were also contacted with a request for published and unpublished data. This request produced a reply from 11 of the 24 researchers contacted (a $45.8 \%$ response rate). The studies selection procedure resulted in the sampling of 123 effect sizes ( 37 for object identity memory and 86 for object location memory) drawn from 36 studies, 3 of which were unpublished or had not been accepted for publication at the time of data entry (11 effect sizes). Note that although it was presented at a professional meeting, the study conducted by Robert and Ecuyer-Dab (2000) was counted as unpublished because it did not appear in a refereed journal. Only two of the sampled studies, those of Janowsky, Chavez, Zamboni, and Orwoll (1998) and Sharps and Gollin (1987), had most of the information required for meta-analysis, but simply stated that no gender differences were found without reporting a test of significance or relevant means and standard deviations. In these cases, the authors were contacted in an attempt to obtain more complete data. However, only Janowsky et al. still had access to their data. Accordingly, only those were included in the analysis, and the study by Sharps and Gollin was excluded.

In theory, only effect sizes that are independent from each other (i.e., come from different samples) for each type of task should be included in the final sample (Hedges \& Becker, 1986). However, to assess the influence of some variables (e.g., object type), nonindependent effect sizes had to be considered. Fortunately, similar to the 
approach used by Voyer et al. (1995), the assumption of nonindependence was only violated for the overall analysis and can generally be discounted as a factor in the various effect size partitions. However, in a number of cases (see, e.g., McBurney, Gaulin, Devineni, \& Adams, 1997; Robert \& Savoie, 2006; Vecchi \& Girelli, 1998), the authors presented several relevant effect sizes from the same sample. When this occurred, nonindependent effect sizes were combined in an attempt to include as many effect sizes as possible. Rosenthal and Rubin (1986) - among others - proposed an approach that allows one to combine nonindependent effect sizes. However, this method requires knowledge of the correlation between measures. Since this information was not available in most cases, homogeneity of the correlated effect sizes was assumed, and the simple arithmetic mean was used. Although this method has typically been found to produce a slight overestimation of the actual effect size (Marín-Martínez \& Sánchez-Meca, 1999; Rosenthal \& Rubin, 1986), it is suitable when homogeneity of the nonindependent effect sizes is assumed (MarínMartínez \& Sánchez-Meca, 1999).

Note that coding of the included studies was performed by the first author and verified by a research assistant. Points of disagreement concerning coding or study inclusion were discussed until agreement was reached.

A further issue relevant to classification of the tasks concerns the distinction between the conventional task and versions of this task.
In this respect, a strict criterion was utilized. Specifically, use of the same drawings of common objects that were utilized by Silverman and Eals (1992) in a recognition task where objects exchanged location was required for classification as the conventional task. This requirement provided a clear and objective criterion for task labeling. It resulted in the classification of variations to this approach with uncommon objects (see, e.g., Eals \& Silverman, 1994) or with location shift (e.g., James \& Kimura, 1997) under the "other versions" label. Following this classification, studies entered in the analysis are found in Tables 1 (object identity), 2 (conventional task), and 3 (other tasks). They are also marked with an asterisk in the reference list.

Considering that the present analysis included mostly published studies, it is possible that published studies are a biased sample of the studies that are actually carried out, because it is presumed that only experiments with significant results are published (see Rosenthal, 1979). This issue (previously discussed and called the file drawer problem by Rosenthal, 1979), is likely to produce an overestimation of the effect sizes. In this situation, the fail-safe number (Rosenthal, 1991) - that is, the number of studies averaging null results that is necessary to offset the significance of the findings at the .05 level-is typically computed. This value was calculated in the present study in order to estimate the resistance of the metaanalytic results to the file drawer problem. The larger the fail-safe value, the more confidence one can have in the obtained results.

Table 1 Studies Using the Object Identity Task Included in the Present Analysis

\begin{tabular}{|c|c|c|c|c|c|c|c|c|}
\hline Authors & $\begin{array}{l}\text { Guessing } \\
\text { Correction }\end{array}$ & $\begin{array}{l}\text { Encoding } \\
\text { Context }\end{array}$ & $\begin{array}{l}\text { Object } \\
\text { Type }\end{array}$ & NM & NF & Age & $g$ & $v$ \\
\hline \multirow[t]{3}{*}{ Cherney \& Ryalls (1999) } & No & Inc & Mas & 20 & 20 & 20 & -.285 & .101 \\
\hline & No & Inc & Neu & 20 & 20 & 20 & .091 & .100 \\
\hline & No & Inc & Fem & 20 & 20 & 20 & .387 & .102 \\
\hline Choi \& L'Hirondelle (2005) & No & Inc & Com & 50 & 61 & 19 & .224 & .037 \\
\hline \multirow[t]{9}{*}{ Choi \& Silverman (2003) } & Yes & Inc & Com & 15 & 13 & 9 & .630 & .150 \\
\hline & Yes & Inc & Com & 17 & 23 & 10 & -.150 & .103 \\
\hline & Yes & Inc & Com & 33 & 32 & 11 & .110 & .062 \\
\hline & Yes & Inc & Com & 39 & 32 & 12 & .620 & .060 \\
\hline & Yes & Inc & Com & 40 & 46 & 13 & .180 & .047 \\
\hline & Yes & Inc & Com & 29 & 26 & 14 & .430 & .075 \\
\hline & Yes & Inc & Com & 30 & 24 & 15 & .300 & .076 \\
\hline & Yes & Inc & Com & 38 & 62 & 16 & -.090 & .042 \\
\hline & Yes & Inc & Com & 32 & 50 & 17 & .310 & .052 \\
\hline \multirow[t]{5}{*}{ Eals \& Silverman (1994) } & Yes & Inc & Unc & 41 & 42 & 20 & .090 & .048 \\
\hline & Yes & Inc & Unc & 40 & 40 & 20 & .188 & .050 \\
\hline & Yes & Inc & Com & 40 & 40 & 20 & .323 & .051 \\
\hline & Yes & Exp & Com & 40 & 40 & 20 & -.218 & .050 \\
\hline & Yes & Exp & Unc & 40 & 40 & 20 & -.222 & .050 \\
\hline Epting \& Overman (1998) & Yes & Inc & Com & 20 & 27 & 20 & -.276 & .088 \\
\hline Gaulin, Silverman, Phillips, \& Reiber (1997) & Yes & Inc & Com & 86 & 118 & 20 & .449 & .021 \\
\hline Iachini, Sergi, Gennaro, \& Gnisci (2005) & No & Exp & Com & 64 & 64 & 23 & -.062 & .031 \\
\hline Levy, Astur, \& Frick (2005) & Yes & Inc & Com & 31 & 24 & 20 & .574 & .077 \\
\hline Lewin, Wolgers, \& Herlitz (2001) & Yes & Inc & Geo & 91 & 94 & 30 & -.110 & .022 \\
\hline Rahman, Abrahams, \& Jussab (2005) & No & Exp & Com & 26 & 26 & 26 & .810 & .083 \\
\hline Rahman, Wilson, \& Abrahams (2003) & No & Inc & $\mathrm{Neu}$ & 120 & 120 & 29 & .226 & .017 \\
\hline Robert \& Ecuyer-Dab (2000) & No & Inc & Com & 132 & 168 & 34 & .378 & .014 \\
\hline Robert \& Savoie (2006) & No & Exp & Com & 50 & 50 & 22 & .401 & .041 \\
\hline \multirow[t]{6}{*}{ Silverman \& Eals (1992) } & Yes & Inc & Com & 63 & 115 & 20 & .472 & .025 \\
\hline & Yes & Inc & Com & 20 & 20 & 20 & .719 & .106 \\
\hline & Yes & Exp & Com & 20 & 20 & 20 & .439 & .102 \\
\hline & Yes & Inc & Com & 56 & 66 & 9 & .000 & .033 \\
\hline & Yes & Inc & Com & 83 & 78 & 11 & .382 & .025 \\
\hline & Yes & Inc & Com & 81 & 86 & 13 & .315 & .024 \\
\hline \multirow{4}{*}{$\begin{array}{l}\text { Voyer, Imperato-McGinley, Brake, } \\
\text { \& Roxborough (2005) }\end{array}$} & Yes & Exp & Com & 23 & 32 & 19 & .0494 & .075 \\
\hline & Yes & Inc & Com & 25 & 31 & 19 & -.083 & .072 \\
\hline & Yes & Inc & Com & 25 & 31 & 21 & -.200 & .073 \\
\hline & Yes & Exp & Com & 25 & 31 & 20 & .642 & .076 \\
\hline
\end{tabular}

Note-NM, Number of males; NF, Number of females; $g$, biased estimate of effect size; $v$, variance of the effect size. Object Type: Com, common; Fem, feminine; Geo, geometric; Mas, masculine; Neu, gender neutral; Unc, uncommon. Encoding Context: Exp, explicit; Inc, incidental. 
Table 2

Studies Using the Conventional Object Location Memory Task Included in the Present Analysis

\begin{tabular}{|c|c|c|c|c|c|c|c|c|}
\hline Authors & $\begin{array}{r}\text { Guessing } \\
\text { Correction }\end{array}$ & $\begin{array}{c}\text { Encoding } \\
\text { Context }\end{array}$ & $\begin{array}{l}\text { Object } \\
\text { Type }\end{array}$ & NM & NF & Age & $g$ & $v$ \\
\hline Alexander et al. (2002) & Yes & Inc & Com & 26 & 25 & 28 & .563 & .081 \\
\hline \multirow[t]{4}{*}{ Barnfield (1999) } & No & Inc & Com & 20 & 23 & 4 & .489 & .096 \\
\hline & No & Inc & Com & 22 & 31 & 10 & -.137 & .078 \\
\hline & No & Inc & Com & 20 & 23 & 15 & .279 & .094 \\
\hline & No & Inc & Com & 40 & 40 & 21 & .579 & .052 \\
\hline Choi \& Lhirondelle (2005) & No & Inc & Com & 50 & 61 & 19 & .206 & .037 \\
\hline \multirow[t]{6}{*}{ Choi \& Silverman (2003) } & Yes & Inc & Com & 15 & 13 & 9 & .010 & .144 \\
\hline & Yes & Inc & Com & 17 & 23 & 10 & -.210 & .103 \\
\hline & Yes & Inc & Com & 33 & 32 & 11 & -.120 & .062 \\
\hline & Yes & Inc & Com & 39 & 32 & 12 & .300 & .058 \\
\hline & Yes & Inc & Com & 40 & 46 & 13 & .360 & .047 \\
\hline & Yes & Inc & Com & 29 & 26 & 14 & .410 & .074 \\
\hline \multirow[t]{3}{*}{ Choi \& Silverman (2003) } & Yes & Inc & Com & 30 & 24 & 15 & .160 & .075 \\
\hline & Yes & Inc & Com & 38 & 62 & 16 & .470 & .044 \\
\hline & Yes & Inc & Com & 32 & 50 & 17 & .190 & .051 \\
\hline Dabbs et al. (1998) & No & Inc & Com & 90 & 104 & 22 & .105 & .021 \\
\hline Duff \& Hampson (2001) & No & Inc & Com & 46 & 46 & 21 & .085 & .044 \\
\hline Ecuyer-Dab \& Robert (2004) & No & Inc & Com & 95 & 121 & 34 & .226 & .019 \\
\hline Gaulin et al. (1997) & No & Inc & Com & 86 & 118 & 20 & .387 & .020 \\
\hline \multirow[t]{3}{*}{ James \& Kimura (1997) } & No & Inc & Com & 20 & 20 & 23 & .666 & .105 \\
\hline & No & Inc & Com & 24 & 25 & 23 & .038 & .082 \\
\hline & No & Inc & Com & 20 & 21 & 23 & -.040 & .098 \\
\hline Levy et al. (2005) & Yes & Inc & Com & 31 & 24 & 20 & .542 & .077 \\
\hline Postma et al. (2004) & No & Exp & Com & 32 & 32 & 21 & .033 & .063 \\
\hline Robert \& Ecuyer-Dab (2000) & No & Inc & Com & 132 & 168 & 34 & .350 & .014 \\
\hline \multirow[t]{4}{*}{ Silverman \& Eals (1992) } & Yes & Inc & Com & 83 & 134 & 20 & .433 & .020 \\
\hline & Yes & Inc & Com & 21 & 20 & 20 & 1.003 & .109 \\
\hline & Yes & Inc & Com & 20 & 20 & 20 & 1.101 & .115 \\
\hline & Yes & Exp & Com & 20 & 20 & 20 & 1.425 & .124 \\
\hline \multirow{2}{*}{$\begin{array}{l}\text { van der Gaag, Langeveld, Sijbrandij, } \\
\text { \& van Haren (2003) }\end{array}$} & No & Exp & Com & 24 & 16 & 8 & -.180 & .105 \\
\hline & No & Exp & Com & 19 & 19 & 20 & -.030 & .105 \\
\hline \multirow[t]{4}{*}{ Voyer et al. (2005) } & Yes & Exp & Com & 23 & 32 & 19 & .283 & .075 \\
\hline & Yes & Inc & Com & 25 & 31 & 19 & .123 & .072 \\
\hline & Yes & Exp & Com & 25 & 31 & 21 & -.025 & .072 \\
\hline & Yes & Inc & Com & 25 & 31 & 20 & .078 & .072 \\
\hline
\end{tabular}

Note-NM, Number of males; NF, Number of females; $g$, biased estimate of effect size; $v$, variance of the effect size. Object Type: Com, common. Encoding Context: Exp, explicit; Inc, incidental.

Rosenthal (1991) suggested the use of $5 k+10$, where $k$ equals the number of sampled studies, as a criterion to evaluate the significance of the fail-safe number. Values larger than this criterion are deemed resistant to the file drawer problem.

\section{Analysis Procedure}

Cohen's $d$ was used as the measure of effect size (Cohen, 1977). This index represents the standardized difference between the mean of females and males in the present study. Effect sizes were computed by using the formula presented by Cohen (1977) when means and standard deviations were available, or by using the formulae presented by Wolf (1986) when only the $t, \chi^{2}, p$, or $F$ statistic was available. A positive effect size reflected gender differences in favor of women, and a negative effect size indicated gender differences in favor of men. However, this measure is considered a biased estimate of effect sizes (Hedges \& Becker, 1986). Accordingly, it was corrected based on the approach presented by Hedges and Becker (1986) to obtain an unbiased estimate, which was then used in further analyses.

The analysis followed the procedure presented by Hedges and Becker (1986). These authors developed meta-analytic techniques that were designed for both the assessment of cognitive gender differences and the evaluation of the homogeneity of the effect sizes. Homogeneity of the effect sizes allows the conclusion that the effect sizes in a specific sample of studies were drawn from the same population. In other words, homogeneity of the effect sizes indicates that the studies included in a specific meta-analysis can be considered replications of each other, and that a pooled estimate of effect size provides a valid summary of the results from the sample of studies. However, when heterogeneity is detected, it is likely that the pooled estimate is not representative of the state of affairs in a sample. One purpose of this approach is to identify variables that have a significant impact on the magnitude of effect sizes. Since there is actually no predetermined way for deciding which variables are important in a meta-analysis (Wolf, 1986), the Hedges and Becker (1986) approach allows one to examine whether a given variable has a significant effect on the magnitude of effect sizes. Specifically, at each step a test is calculated to determine whether the partitioning that was applied to the data had a significant effect on the magnitude of effect sizes. Such a test examines whether the difference between the heterogeneity for the whole sample (total heterogeneity) and that for the sum of the partitions (within-group heterogeneity) results in a significant amount of between-group heterogeneity. This approach can thus be interpreted as a test of whether the specific variable used in partitioning produced significant between-group heterogeneity. This is essentially the same as determining whether a factor produces significant group differences in the context of an ANOVA (Hedges \& Becker, 1986).

From this perspective, the present meta-analysis followed a hierarchical approach. Thus, an overall analysis examining the magnitude and the homogeneity of gender differences among the effect sizes that were selected in each of the separate analyses (object identity 
Table 3

Studies Using Other Versions of the Object Location Memory Task Included in the Present Analysis

\begin{tabular}{|c|c|c|c|c|c|c|c|c|c|}
\hline Authors & $\begin{array}{c}\text { Guessing } \\
\text { Correction }\end{array}$ & $\begin{array}{c}\text { Encoding } \\
\text { Context }\end{array}$ & $\begin{array}{c}\text { Object } \\
\text { Type }\end{array}$ & Score & NM & NF & Age & $g$ & $v$ \\
\hline \multirow{3}{*}{ Alexander (2005) } & No & Inc & Neu & Acc & 20 & 20 & 20 & .770 & .107 \\
\hline & No & Inc & Fem & Acc & 20 & 20 & 20 & -.300 & .101 \\
\hline & No & Inc & Mas & Acc & 20 & 20 & 20 & -1.230 & .118 \\
\hline Cattaneo, Postma, \& Vecchi (2006) & N/A & Exp & Com & Dis & 20 & 20 & 24 & .158 & .100 \\
\hline \multirow[t]{3}{*}{ Cherney \& Ryalls (1999) } & Yes & Inc & Mas & Acc & 20 & 20 & 20 & -.473 & .103 \\
\hline & Yes & Inc & Neu & Acc & 20 & 20 & 20 & .854 & .109 \\
\hline & Yes & Inc & Fem & Acc & 20 & 20 & 20 & 1.187 & .117 \\
\hline Choi \& L'Hirondelle (2005) & N/A & Inc & Neu & Dis & 23 & 30 & 19 & .042 & .077 \\
\hline \multirow[t]{2}{*}{ Crook et al. (1990) } & No & Exp & Com & Acc & 31 & 42 & 28 & .308 & .057 \\
\hline & No & Exp & Com & Acc & 14 & 46 & 45 & .549 & .096 \\
\hline \multirow[t]{3}{*}{ Crook et al. (1990) } & No & Exp & Com & Acc & 56 & 108 & 55 & .579 & .028 \\
\hline & No & Exp & Com & Acc & 48 & 102 & 65 & .412 & .031 \\
\hline & No & Exp & Com & Acc & 29 & 53 & 75 & .023 & .053 \\
\hline \multirow[t]{6}{*}{ Duff \& Hampson (2001) } & No & Exp & Geo & Time & 46 & 44 & 20 & .463 & .046 \\
\hline & No & Exp & Geo & Acc & 46 & 44 & 20 & .525 & .046 \\
\hline & No & Exp & Geo & Time & 44 & 44 & 21 & .449 & .047 \\
\hline & No & Exp & Geo & Acc & 46 & 46 & 21 & .586 & .045 \\
\hline & No & Exp & Geo & Time & 46 & 46 & 21 & .732 & .046 \\
\hline & No & Exp & Geo & Acc & 44 & 44 & 21 & .754 & .049 \\
\hline \multirow[t]{5}{*}{ Eals \& Silverman (1994) } & No & Inc & Unc & Acc & 20 & 20 & 20 & .707 & .106 \\
\hline & No & Inc & Com & Acc & 20 & 20 & 20 & 1.120 & .115 \\
\hline & No & Exp & Unc & Acc & 20 & 20 & 20 & -.223 & .101 \\
\hline & No & Exp & Com & Acc & 20 & 20 & 20 & 1.177 & .166 \\
\hline & Yes & Inc & Unc & Acc & 41 & 42 & 20 & .655 & .051 \\
\hline Epting \& Overman (1998) & Yes & Inc & Unc & Acc & 20 & 27 & 20 & .043 & .087 \\
\hline Hill et al. (1995) & No & Exp & Com & Acc & 106 & 106 & 81 & .508 & .019 \\
\hline Iachini et al. (2005) & N/A & Exp & Com & Dis & 64 & 64 & 23 & -.477 & .032 \\
\hline \multirow[t]{2}{*}{ James \& Kimura (1997) } & No & Inc & Com & Acc & 11 & 9 & 23 & .567 & .209 \\
\hline & No & Inc & Com & Acc & 12 & 12 & 23 & .859 & .181 \\
\hline \multirow[t]{2}{*}{ Janowsky et al. (1998) } & No & Exp & Com & Acc & 18 & 30 & 29 & -.318 & .089 \\
\hline & $\mathrm{N} / \mathrm{A}$ & Exp & Com & Dis & 18 & 30 & 29 & -.376 & .089 \\
\hline Levy et al. (2005) & Yes & Inc & Com & Acc & 31 & 24 & 20 & .871 & .081 \\
\hline Lewin et al. (2001) & Yes & Inc & Geo & Acc & 91 & 94 & 30 & .070 & .022 \\
\hline McBurney et al. (1997) & No & Exp & Com & Time & 57 & 46 & 20 & .890 & .043 \\
\hline \multicolumn{10}{|l|}{ Montello, Lovelace, Golledge, } \\
\hline$\&$ Self (1999) & Yes & Inc & Unc & Acc & 36 & 43 & 47 & .562 & .053 \\
\hline \multirow[t]{2}{*}{ Postma et al. (2004) } & N/A & Exp & Com & Acc & 32 & 32 & 21 & -.053 & .062 \\
\hline & N/A & Exp & Com & Dis & 32 & 32 & 21 & -.544 & .065 \\
\hline Postma et al. (1999) & N/A & Exp & Com & Dis & 23 & 34 & 23 & -.717 & .077 \\
\hline Postma et al. (1998) & N/A & Exp & Com & Dis & 20 & 20 & 24 & -.860 & .109 \\
\hline Rahman et al. (2005) & No & Exp & Com & Acc & 26 & 26 & 26 & .489 & .079 \\
\hline Rahman et al. (2003) & N/A & Inc & $\mathrm{Neu}$ & Dis & 120 & 120 & 29 & .241 & .017 \\
\hline Robert \& Savoie (2006) & No & Inc & Com & Acc & 132 & 168 & 34 & .378 & .014 \\
\hline \multirow[t]{2}{*}{ Sharps et al. (1993) } & No & Exp & Com & Acc & 16 & 16 & 24 & -.845 & .136 \\
\hline & No & Exp & Com & Acc & 16 & 16 & 24 & .788 & .134 \\
\hline \multirow[t]{3}{*}{ Silverman \& Eals (1992) } & No & Inc & Com & Acc & 21 & 20 & 20 & 1.003 & .109 \\
\hline & No & Inc & Com & Acc & 20 & 20 & 20 & 1.101 & .115 \\
\hline & No & Exp & Com & Acc & 20 & 20 & 20 & 1.425 & .124 \\
\hline Tottenham et al. (2003) & No & Exp & Com & Time & 31 & 31 & 20 & .736 & .069 \\
\hline Vecchi \& Girelli (1998) & No & Exp & Geo & Acc & 18 & 18 & 30 & -.155 & .111 \\
\hline \multirow{2}{*}{ West, Welch, \& Knabb (2002) } & No & Inc & Com & Acc & 37 & 43 & 19 & .385 & .051 \\
\hline & No & Inc & Com & Acc & 43 & 110 & 73 & .714 & .034 \\
\hline
\end{tabular}

Note-NM, Number of males; NF, Number of females; $g$, biased estimate of effect size; $v$, variance of the effect size. Object Type: Com, common; Fem, feminine; Geo, geometric; Mas, masculine; Neu, gender neutral; Unc, uncommon. Encoding Context: Exp, explicit; Inc, incidental. Score: Acc, accuracy; Dis, distance; Time, completion time.

memory and object location memory) was first conducted. In an attempt to determine what variables have a significant influence on the magnitude of effect sizes, a number of possible partitions were systematically examined, following the method recommended by Wolf (1986). Variables considered as part of this exploratory analysis were: age of the sample (under 13, 13 to 18, over 18), as defined by Linn and Petersen (1985), type of measure (recall or recognition), object type (common, uncommon, gender neutral, geometric, masculine, or feminine), encoding context (incidental or explicit), type of setting (drawing, real, or computer task), scoring procedure (accuracy, completion time, or distance), correction for guessing (uncorrected or corrected), and administration procedure (individual or group). The results reported below reflect the outcome of these explorations and represent the partitions that have a significant influence on the magnitude of gender differences in object location memory.

Note that homogeneity of significance levels is often difficult to achieve in a meta-analysis (Linn \& Petersen, 1985). Accordingly, a criterion similar to that used by Voyer et al. (1995) was utilized to 
classify significance levels as close to homogeneity. Specifically, when the obtained homogeneity statistic was significant at the .05 level, but not at the .005 level, significance levels were designated as close to homogeneous. Although this range is arbitrary, it sets clear limits to what can be considered as satisfactorily homogeneous.

\section{RESULTS}

\section{Effect Size Partitioning}

Object identity memory. As was previously stated, object identity tasks were examined separately from object location memory tasks. The meta-analysis of 37 effect sizes obtained from object identity tasks produced a mean weighted effect size of 0.229 (mean unweighted $d=$ $0.215)$, reflecting overall gender differences in favor of females $(z=6.48, p<.01)$. This sample was also found to produce effect sizes that were homogeneous $\left[\chi^{2}(36)=\right.$ 50.48 , n.s.]. One can thus legitimately conclude that the mean effect size reflects the state of affairs in this sample and that no further partitioning of the effect sizes is required. In addition, the fail-safe analysis indicated that 433 studies with nonsignificant or contrary results would be needed to offset the significance of the findings at the .05 level. Taken together, the results indicate that gender differences in object identity memory tasks that are performed in the context of studies on object location memory produced relatively small but significant gender differences in favor of females that are resistant to the file drawer problem.

Object location memory. The analysis of the 86 effect sizes obtained on object location memory tasks revealed a mean weighted $d$ of $0.269(z=10.77, p<.01)$, demonstrating that overall, gender differences in object memory favoring females are significant. The fail-safe analysis indicated that 3,250 studies with nonsignificant or contrary results would be needed to offset the significance of the mean effect size at the .05 level. The findings are thus resistant to the file drawer problem. However, the effect sizes were not homogeneous $\left[\chi^{2}(85)=233.04, p<.01\right]$. This result suggests that the studies included in the present analysis are not all drawn from the same population and that the pooled estimate of effect size does not provide a representative summary of the sample of effect sizes. Thus, while the gender differences are significant, they are also heterogeneous. Partitioning of the effect sizes into homogeneous clusters is therefore required.

Effect sizes were first partitioned as a function of the age of the sample, based on the approach followed by Linn and Petersen (1985). This partition produced significant between-group heterogeneity $\left[\chi^{2}(2)=10.88, p<.01\right]$, indicating a significant relation between the age categories and the magnitude of gender differences in object location memory. As seen in Table 4, this partition resulted in homogeneous clusters for participants below the age of 13 and those between 13 and 18. For the younger group, gender differences were not significant, whereas they were for the older groups. One can thus legitimately conclude that gender differences in object location memory appear sometime after the age of 13, although they are not resistant to the file drawer problem between the ages of 13 and 18. The cluster of samples over the age of 18 showed significant gender differences (resistant to the file drawer problem), but they remained heterogeneous. This cluster thus required further partitioning.

Following a systematic examination of the influence of the variables previously mentioned, only object type produced significant between-group heterogeneity for the remaining sample of 70 effect sizes that included participants over the age of 18. Effect sizes that were based on studies using common, uncommon, gender-neutral, geometric, masculine, and feminine objects were therefore considered separately. As seen in Table 5, when this partition was performed, the geometric and masculine object clusters achieved homogeneity, and the partition resulted in significant between-group heterogeneity $\left[\chi^{2}(5)=\right.$ $35.82, p<.01]$. Note that feminine objects showed nonsignificant gender differences that were not homogeneous. In contrast, masculine objects showed significant and homogeneous differences in favor of males, but they were not resistant to the file drawer problem on the basis of Rosenthal's (1991) criterion. The common and geometric object clusters produced significant differences in favor of females, although only the latter was homogeneous. For the uncommon and gender-neutral clusters, differences were nonsignificant but heterogeneous.

Examination of the effect sizes that were included in the gender-neutral cluster was quite informative in showing that scoring procedure was critical in accounting for heterogeneity. When gender-neutral effect sizes were partitioned by scoring procedure, significant between-group heterogeneity was obtained $\left[\chi^{2}(1)=14.34, p<.01\right]$, reflecting significant gender differences in favor of females for accuracy $(d$. $=0.795, z=3.42, p<.01)$ that were homogeneous $\left[\chi^{2}(1)=0.03, \mathrm{n} . \mathrm{s}\right.$.]. In contrast, the distance cluster for gender-neutral objects showed nonsignificant

Table 4

Summary Statistics for the Meta-Analysis of Gender Differences in Object Location Memory Tasks As a Function of Age Category

\begin{tabular}{|c|c|c|c|c|c|c|}
\hline Age Category & $k$ & $\begin{array}{l}\text { Weighted } \\
\text { Estimator } \\
\text { of ES }(d .)\end{array}$ & $\begin{array}{c}\text { Unweighted } \\
\text { Mean } d\end{array}$ & $\begin{array}{c}\text { Fail-Safe } \\
\text { Number }\end{array}$ & $\begin{array}{c}\text { Test of } \\
\text { Significance } \\
\text { for } \operatorname{ES}(Z)\end{array}$ & $\begin{array}{l}\text { Homogeneity } \\
\text { Statistic }\left(\chi^{2}\right)\end{array}$ \\
\hline Overall & 86 & 0.269 & 0.272 & 3,250 & $10.77^{*}$ & $233.04^{*}$ \\
\hline Younger than 13 & 9 & 0.018 & 0.017 & 0 & 0.22 & $5.05^{\dagger}$ \\
\hline 13 to 18 & 7 & 0.328 & 0.313 & 29 & $3.91^{*}$ & $1.35^{\dagger}$ \\
\hline Older than 18 & 70 & 0.291 & 0.302 & 2,568 & $10.51^{*}$ & $215.76^{*}$ \\
\hline
\end{tabular}


Table 5

Summary Statistics for the Meta-Analysis of Gender Differences in Object Location Memory Tasks for Samples Older Than 18 Years As a Function of Object Type

\begin{tabular}{lrrcccc}
\hline Object Type & $k$ & $\begin{array}{c}\text { Weighted } \\
\text { Estimator } \\
\text { of ES }(d .)\end{array}$ & $\begin{array}{c}\text { Unweighted } \\
\text { Mean } d\end{array}$ & $\begin{array}{c}\text { Fail-Safe } \\
\text { Number }\end{array}$ & $\begin{array}{c}\text { Test of } \\
\text { Significance } \\
\text { for ES }(Z)\end{array}$ & $\begin{array}{c}\text { Homogeneity } \\
\text { Statistic }\left(\chi^{2}\right)\end{array}$ \\
\hline Common & 48 & 0.328 & 0.348 & 1,582 & $9.95^{*}$ & $124.27^{*}$ \\
Uncommon & 6 & 0.139 & 0.081 & 0 & 1.19 & $14.52^{*}$ \\
Gender neutral & 4 & -0.001 & 0.328 & 0 & 0.01 & $15.21^{*}$ \\
Geometric & 8 & 0.416 & 0.425 & 84 & $5.65^{*}$ & $13.72^{\dagger}$ \\
Masculine & 2 & -0.809 & -0.835 & 6 & $-3.45^{*}$ & $2.48^{\dagger}$ \\
Feminine & 2 & 0.382 & 0.435 & 0 & 1.64 & $9.74^{*}$ \\
\hline
\end{tabular}

${ }^{*} p<.05$. †Homogeneity achieved.

gender differences $(d .=-0.190, z=1.62$, n.s. $)$ that were homogeneous $\left[\chi^{2}(1)=0.84\right.$, n.s. $]$, reflecting a trend for a male advantage.

For the uncommon objects cluster, encoding context was found to account for heterogeneity. Specifically, when effect sizes were partitioned by encoding context, significant between-group heterogeneity was observed $\left[\chi^{2}(1)=11.22\right.$, $p<.01]$. It reflected significant gender differences in favor of females for incidental encoding $[d .=0.488, z=3.11$, $p<.01]$ that were homogeneous $\left[\chi^{2}(2)=3.18\right.$, n.s. $]$. In contrast, explicit encoding of uncommon objects showed nonsignificant gender differences $[d .=-0.303, z=1.72$, n.s.] that were homogeneous $\left[\chi^{2}(1)=0.12\right.$, n.s.], reflecting a trend for a male advantage.

Attempts to achieve homogeneity among common objects in samples over the age of 18 indicated that a partition as a function of scoring procedure produced significant between-group heterogeneity $\left[\chi^{2}(2)=50.09, p<\right.$ $.01]$, resulting in two homogeneous clusters out of three (time and distance; see Table 6). All three clusters showed significant gender differences, although only the accuracy grouping was resistant to the file drawer problem. An important aspect of these clusters is that differences were in favor of females when accuracy and completion time were the dependent variable, whereas they were in favor of males on distance measures.

Finally, for the accuracy cluster in samples over the age of 18 for common objects, a partition in terms of type of measure resulted in significant between-group heterogeneity $\left[\chi^{2}(1)=12.06, p<.01\right]$, resulting in two homogeneous or close to homogeneous clusters (see Table 7). The data presented in Table 7 suggest that the magnitude of gender differences for accuracy in adult samples with common objects is greater in recall than in recognition tasks.
Encoding context. Although a clustering in terms of encoding context was required to achieve homogeneous effect sizes for uncommon objects, this factor was also examined for the whole sample to determine its generalizability to other object types. Accordingly, the 86 effect sizes obtained on the object location memory task were partitioned as a function of encoding context. This produced 48 effect sizes using incidental encoding and 38 effect sizes based on explicit encoding. A mean weighted effect size of $0.257(z=7.92, p<.01)$ was obtained in the incidental cluster, whereas it was $0.286(z=7.31, p<$ $.01)$ in the explicit cluster. Both clusters were heterogeneous $\left[\chi^{2}(47)=111.66, p<.005\right.$ for the incidental cluster, and $\chi^{2}(37)=121.03, p<.005$ for the explicit cluster]. The most critical finding, however, was that this partition did not result in significant between-group heterogeneity $\left[\chi^{2}(1)=0.35\right.$, n.s. $]$. Therefore, the influence of encoding context on the magnitude of gender differences in object location memory does not generalize across object types.

\section{DISCUSSION}

The purpose of the present study was to examine the magnitude and specificity of gender differences in object location memory. This purpose was achieved through a hierarchical meta-analysis of the available literature. The specificity aspect derives from the notion that object location memory is a multicomponential task, raising the question of which particular components show gender differences.

\section{Object Identity Memory}

The analysis for the 37 effect sizes relevant to object identity memory produced straightforward results. The mean weighted effect size of 0.229 was found to be sig-

Table 6

Summary Statistics for the Meta-Analysis of Gender Differences in the Object Location Memory Tasks for Common Objects in Samples Older Than 18 Years As a Function of Scoring Procedure

\begin{tabular}{|c|c|c|c|c|c|c|}
\hline $\begin{array}{c}\text { Scoring } \\
\text { Procedure }\end{array}$ & $k$ & $\begin{array}{l}\text { Weighted } \\
\text { Estimator } \\
\text { of ES }(d .)\end{array}$ & $\begin{array}{l}\text { Unweighted } \\
\text { Mean } d\end{array}$ & $\begin{array}{l}\text { Fail-Safe } \\
\text { Number }\end{array}$ & $\begin{array}{c}\text { Test of } \\
\text { Significance } \\
\text { for } \operatorname{ES}(Z)\end{array}$ & $\begin{array}{l}\text { Homogeneity } \\
\text { Statistic }\left(\chi^{2}\right)\end{array}$ \\
\hline Accuracy & 41 & 0.372 & 0.419 & 1,616 & $10.54^{*}$ & $68.01^{*}$ \\
\hline Time & 2 & 0.823 & 0.805 & 15 & $5.06^{*}$ & $0.23^{\dagger}$ \\
\hline Distance & 5 & -0.488 & -0.414 & 26 & $-4.33^{*}$ & $5.94^{\dagger}$ \\
\hline
\end{tabular}


Table 7

Summary Statistics for the Meta-Analysis of Gender Differences in the

Object Location Memory Tasks Measure with Accuracy for Common Objects in Samples Older Than 18 Years As a Function of Measure

\begin{tabular}{|c|c|c|c|c|c|c|}
\hline Measure & $k$ & $\begin{array}{l}\text { Weighted } \\
\text { Estimator } \\
\text { of ES }(d .)\end{array}$ & $\begin{array}{l}\text { Unweighted } \\
\text { Mean } d\end{array}$ & $\begin{array}{l}\text { Fail-Safe } \\
\text { Number }\end{array}$ & $\begin{array}{c}\text { Test of } \\
\text { Significance } \\
\text { for } \operatorname{ES}(Z)\end{array}$ & $\begin{array}{l}\text { Homogeneity } \\
\text { Statistic }\left(\chi^{2}\right)\end{array}$ \\
\hline Recall & 17 & 0.543 & 0.587 & 486 & $8.97^{*}$ & 32.25 \\
\hline Recognition & 24 & 0.284 & 0.301 & 309 & $6.54^{*}$ & $23.70^{\dagger}$ \\
\hline
\end{tabular}

nificant. It was also homogeneous, so one can legitimately conclude that this effect size is representative of the state of affairs in the sample. One may also plausibly conclude that gender differences in favor of women exist in object identity memory and that their magnitude is fairly stable across different administration procedures. However, the effect size would be classified as small on the basis of Cohen's (1977) categorization. In addition, findings that are relevant to object identity only apply to the paradigm considered here. Because the present analysis considered object identity memory tasks only if they were used in the context of an object location memory study, it is not possible to generalize to other paradigms. Further implication of the findings that are applicable to object identity memory for interpreting gender differences in object location will be discussed as they become relevant.

\section{Object Location Memory}

An examination of the 86 effect sizes that were relevant to object location memory revealed significant gender differences in favor of females, with a mean weighted effect size of 0.269 . Thus, the present results support the notion that females have an overall advantage in tasks requiring them to memorize the location of objects. However, the summary statistic was based on heterogeneous effect sizes and therefore required further partitioning in meaningful groupings. After a systematic examination of the variables that were deemed potentially relevant, the age of the participants, object type, scoring procedure, and type of measure were found to have significant effects on the magnitude of gender differences. Implications of the findings for these partitions are discussed below.

Age of the participants. The finding that gender differences in children $($ age $<13)$ are not significant, but that in adolescents (ages between 13 and 18) and adults (age over 18) they are, suggests that similar to what has been reported for spatial abilities by Linn and Petersen (1985) and Voyer et al. (1995), gender differences in object location memory are quite small during childhood and occur only with puberty. One can thus plausibly assume that the emergence of these gender differences is due in part to the hormonal and cognitive changes associated with puberty. In fact, this finding might appear to contradict what one would expect on the basis of evolutionary models. Indeed, one would expect that a gender difference that is a product of evolution should be present throughout the life span, regardless of hormonal or cognitive landmarks that stem from maturation. However, one could equally expect that the brain's sensitivity to certain hormones during puberty might be the result of evolution. In fact, the emergence of gender differences in object location memory at puberty supports Silverman and Eals' (1992) claim that these differences are affected by pubertal events. This effect allegedly reflects the role of hormones in these gender differences. On the basis of the present results, it would appear that Silverman and Eals's conclusions concerning this factor were warranted. However, keep in mind that the emergence of gender differences at puberty can be accounted for by differential cumulative experience in males and females as well as by hormonal factors (Singleton, 1986). Therefore, concluding that either factor takes precedence over the other is premature until further work examining their relative contribution to gender differences in object location memory is conducted. In addition, the present findings on the effect of age are based on a small number of studies, and gender differences in the samples between ages 13 and 18 are not resistant to the file drawer problem. In fact, only 16 of the 86 effects sizes $(18.6 \%)$ considered here were obtained with samples below the age of 18 . This result clearly suggests that the study of gender differences in object location memory in children is an area that requires significantly more research.

Object type. Although a variety of possible factors were considered as part of the systematic approach suggested by Wolf (1986), object type was the only variable that produced significant between-group heterogeneity for the 70 effect sizes that were obtained with samples over the age of 18. Results of this partition revealed homogeneous clusters for two types of objects: geometric and masculine. Homogeneity was achieved in separate clusters when gender-neutral objects were partitioned by scoring procedure, whereas encoding context produced homogeneous clusters for uncommon objects. However, only geometric objects showed significant effects in favor of females that were resistant to the file drawer problem. In contrast, masculine objects showed gender differences in favor of males, although they were not resistant to the file drawer problem. The findings for masculine objects suggest a possible role for gender relevance as a contributory factor to gender differences in object location memory (Cherney \& Ryalls, 1997). However, findings of a nonsignificant mean effect size for feminine objects do not fit with this interpretation. Furthermore, these conclusions are made on the basis of a very small number of effect sizes for several of the categories. For example, the feminine category comprised only two effect sizes, and 
one of them could be only loosely associated with women. Specifically, it involved the memory for locations of sad faces in the study by Alexander (2005). This type of objects might account for the heterogeneity of this grouping. However, the inclusion of threatening faces as masculine objects from the same study still produced homogeneous effect sizes. The influence of these specific stimuli on the present findings is thus unclear. However, the present results suggest that object type is clearly worthy of further investigation.

The majority of the effect sizes that were retrieved in the object location memory component of the analysis belonged to the common object grouping. Essentially, this grouping was made out of objects one might find in the everyday environment. In reality, one could plausibly classify many of these common objects into one of three categories: feminine, masculine, or gender neutral. However, researchers using these objects in their studies did not apply this classification in their data analysis, and it was therefore not available for use in the present metaanalysis. Therefore, it is not surprising that effect sizes that were based on common objects were heterogeneous and required further partitioning.

Consideration in the common object cluster for samples over the age of 18 revealed that the magnitude of gender differences was significantly related to scoring procedure (see Table 6). Results showed that two of the three clusters that resulted from this partitioning (completion time, distance) were homogeneous and that the three groupings produced significant gender differences, although they were resistant to the file drawer problem only in the accuracy cluster. The most interesting finding was that gender differences were in favor of men on distance, whereas they were in favor of women on accuracy and completion time. This finding confirmed the prediction that if coordinate and categorical approaches were used in these tasks, gender differences in favor of males would be obtained for measures of distance between actual object location and the participants' placement of these objects, whereas females would show an advantage for accuracy measures. This finding supports the notion that interpretations of gender differences in object location memory are not as straightforward as one is led to believe from the Silverman and Eals (1992) report. The interpretations presented by these authors imply that object location memory is a one-dimensional process in which women should be expected to excel because of evolutionary factors. The distinction between measures of accuracy and distance (and the underlying categorical-coordinate distinction) raises the possibility that the direction of gender differences in object location memory depends on the exact nature of the task. This possibility is similar to variations in the direction of gender differences observed by Hyde et al. (1990) for mathematical abilities, and it emphasizes the multicomponential nature of object location memory. Although this finding does not refute evolutionary explanations, it suggests that these explanations require further refinement. However, note that only five effect sizes using a distance measure with common objects could be retrieved and that the findings in this cluster could be due to the use of a majority of published studies. Such a possibility suggests that more studies using distance as a dependent variable should be conducted to strengthen the conclusion that men obtain a better object location memory performance than women when distance is used as a measure, presumably reflecting their advantage in handling coordinate information. This need for more relevant research is clearly the most obvious conclusion that can be drawn from the present findings.

The role of scoring procedure on the magnitude of gender differences in object location memory has another implication that is not readily obvious from an examination of Table 6. Specifically, the time and distance clusters consisted exclusively of tasks classified as "other versions of the object location memory task." One could thus be tempted to argue that the findings in these clusters reflect the task that was used rather than the scoring procedure. However, the accuracy cluster included 19 effects sizes that were obtained with the conventional task and 22 effect sizes observed with other versions of the task, and these factors did not account for heterogeneity of effect sizes in this partition. The magnitude of gender differences on accuracy thus generalizes across versions of the object location memory task.

Remember, however, that the accuracy cluster required further partitioning as a function of the type of measure. Specifically, the results suggest that recall measures produce larger gender differences than recognition tasks. This finding indicates that the findings reported by Rahman et al. (2003) for object identity memory generalize to object location in the sample of studies retrieved here. Considering that recall tasks are typically more difficult than recognition tasks (Lockhart, 2000), the smaller gender differences in the latter might partly reflect a ceiling effect.

The distinction between recall and recognition also has possible implications for the interpretation of findings pertaining to measures of accuracy and distance. Specifically, all tasks that are based on measures of distance require recall of the position of the objects. In contrast, accuracy can be measured either as recognition or recall. In this case, one would expect accuracy in a recall task to be based on a distance criterion such that object placement within a given distance from its actual location would be considered correct. Since the distance results suggest that males tend to make a more precise location judgment and females can be said to "roughly" remember the location of objects, one can plausibly believe that with a sufficiently strict distance criterion, gender differences on accuracy could be reduced or even reversed. However, it appears that this possibility has not been examined to date. Most of the researchers who used accuracy in a recall task either utilized approximate placement (e.g., Silverman \& Eals, 1992) or the specific location of objects in a grid or a clearly defined space (e.g., a room of a house in Crook et al., 1990) to determine accuracy. These approaches would reflect a relatively lax criterion for accuracy and provide no information about actual placement distance. Only Hill et al. (1995) and Sharps et al. (1993) used a specific distance criterion to determine accuracy. However, 
they did not examine the possible influence of variations of this criterion on the magnitude and direction of gender differences in their object location memory tasks. The question of whether a stricter criterion would affect the magnitude or direction of gender differences in object location memory thus remains an empirical one. Exploring this aspect in future work might be worthwhile.

\section{Encoding Context}

The role of encoding context has been presented as possibly reflecting different attentional styles in females and males. Eals and Silverman (1994) made this claim on the basis of their finding that gender differences in location memory for unfamiliar objects were in favor of females under incidental learning, whereas they were in favor of males under explicit instructions. The need to partition effect sizes for uncommon objects as a function of encoding context in order to obtain homogeneous clusters extended their results to the present sample. This finding did not generalize to other types of objects, but it could be accounted for by the role of verbal mediation (Eals \& Silverman, 1994). More importantly, the Eals and Silverman study accounted for three of the six effect sizes included in the uncommon objects cluster (two with incidental encoding, one with explicit encoding). Additionally, one of the explicit context effect sizes in this cluster was based on a distance measure from the Janowsky et al. (1998) study, which might have contributed to a gender difference in favor of males. However, encoding context still accounted for significant between-group heterogeneity when the effect size based on distance was removed. Taken together, the results relevant to encoding context suggest that it might be a factor contributing to the magnitude of gender differences in object location memory when verbal mediation is not possible. However, further research is required in order to determine whether encoding context generalizes across samples.

\section{The Role of Memory}

The present study revealed the presence of significant gender differences in object location memory that were in favor of women under most circumstances. The only exceptions were with feminine objects, where they were not significant, and with masculine objects and measures of distance, where they were in favor of males. Gender differences were also in favor of women in object identity memory, suggesting that the presence of such differences extends beyond object location memory. This finding indirectly supports the previously discussed notion that object identity and object location are both a part of the object location memory process since they produce gender differences in favor of females. However, this finding also makes one quite tempted to speculate that gender differences in object location memory might simply reflect a generalized female advantage in memory. Unfortunately, to our knowledge modern meta-analytic techniques do not allow one to examine this possibility with the sample of effect sizes collected here. However, note that the overall magnitude of effect for object location memory $(d$. $=$ 0.269 ) is only slightly larger than the one for object iden- tity memory $(d .=0.229)$. In addition, gender differences in favor of women have been reported in various memory tasks for the recognition of faces (Guillem \& Mograss, 2005), the appearance of others (Horgan, Schmid Mast, Hall, \& Carter, 2004), and associative memory (Hedges \& Nowell, 1995). Hedges and Nowell's (1995) meta-analytic results are especially noteworthy since the overall magnitude of gender differences obtained here is within the range that they reported for associative memory $(d$. from 0.18 to 0.32). Considering that a definite answer to the question of whether gender differences in object location memory can be accounted for by a female advantage in memory cannot be answered conclusively at this point; studies investigating this question are strongly recommended.

In the meantime, a closer examination of the 16 studies that required participants to perform both the object identity and the object location tasks indicated that only two of them investigated whether gender differences in object location memory were independent from gender differences in identity memory. In one such study, Silverman and Eals (1992) claimed that they examined the independence of identity memory and location memory by computing the proportion of the number of correctly located objects divided by the number of correctly identified objects. This does not strike one as a direct way to estimate the independence of these two types of memory since it is simply a ratio of two memory scores. For example, it does not capture the probability of a correct location given correct identification. Such a measure would likely provide a better test of whether one is more likely to have good location memory, given good identity memory. Another approach would be to use an ANCOVA with identity memory performance as the covariate, object location score as a dependent variable, and gender as an independent variable. Rahman et al. (2003) computed such an ANCOVA. However, since they obtained a nonsignificant main effect of gender in their original analysis, this study does not provide a strong test of the role of identity memory. Finally, the unpublished data by Voyer, Imperato-McGinley, Brake, and Roxborough (2005) also failed to produce significant gender differences in either identity or location memory, thereby making an ANCOVA uninformative. Nevertheless, the Pearson correlation between identity and location memory performance was .37 in the overall sample of 223 participants $(p<.01)$. This correlation suggests that these two tasks share common variance. However, the question of whether gender differences in object location memory can be accounted for by differences in general memory still remains open.

\section{Procedural Concerns}

The meta-analytic results presented above might lead one to believe that a relatively straightforward path was followed in determining the variables that produced significant between-group heterogeneity. In reality, the final solution presented as part of the results followed a long trial-and-error process. Although this approach is common in meta-analyses (Wolf, 1986), it was complicated by an important factor in the present data. Specifically, part of what makes the conventional object location memory 
task stand out is that it is administered under conditions that vary little between studies. Although one could argue that this is partly a result of the strict definition used here, this task always involves recognition, and it is typically scored with a measure of accuracy. The only procedural variables that have been studied are the type of objects, correction for guessing, encoding context, and administration conditions (individual or group). In contrast, several versions of the object location memory task vary in terms of measure (recall or recognition), type of setting (drawings, real objects, or computer), object type, encoding context, scoring procedure (accuracy, completion time, or distance), correction for guessing, and administration procedure. The availability of so many variables in versions of the object location memory task suggests that limitations on the number of variables available for partitioning in the conventional task made it impossible to investigate the influence of several factors on gender differences in this task. Thus, it is possible that some of the variables that could not be considered in the overall sample would have resulted in significant between-group heterogeneity. The whole point of this discussion is to encourage researchers to administer the conventional task in nonstandard conditions. Of course, such modifications of the conventional task would result in the inclusion of relevant findings under the label "other versions of the object location memory task," to use the description presented here. However, such research would serve two related purposes: (1) It would allow an investigation of how resistant gender differences on this task are to variations in administration procedures, and (2) it would allow a comparison of the magnitude of gender differences under various conditions, which would contribute to our understanding of these differences. For example, measuring completion time indicated large gender differences in favor of females for other versions of the task in the present analysis (see Table 6). In fact, this was the largest effect size observed here, although it was not resistant to the file drawer problem. Demonstrating that this finding also applies to the conventional task would allow its generalization and would have implications for claims that men process spatial information more quickly than do women (Goldstein, Haldane, \& Mitchell, 1990; but see Masters, 1998). It thus appears that explorations of factors affecting the robustness of gender differences in object location memory tasks (conventional and others) are likely to result in more refined interpretations of the observed findings. Research in this direction should thus be encouraged.

In summary, the present analysis clearly suggests the presence of small to intermediate gender differences in object identity and object location memory under most circumstances. The present analysis is also likely to represent an exhaustive sample of the published studies investigating gender differences in object location memory, but when compared with previous work on cognitive gender differences (Linn \& Petersen, 1985; Voyer et al., 1995), it included a relatively small number of effect sizes. However, when one considers that the research sample here represents only 16 years of work by various researchers, it is clear that this is a topic that generates much interest.
The present analysis strongly suggests that even more research is required before the question of the existence of gender differences in object location memory - as well as the factors that affect their magnitude - can be clearly understood. We hope that the present findings will stimulate this research and guide it toward productive areas of inquiry. For the time being, the resistance to the file drawer problem of the main results in the present study gives us confidence that our tentative conclusions will bear out.

\section{AUTHOR NOTE}

This study was funded by a National Institute of Health grant to J.I.-M. (P.I.) and D.V. A.P. was supported by a grant from the Netherlands Organization for Fundamental Research and by an EU NEST Fp6 grant (No. 12959-Wayfinding). The authors thank Michèle Robert for her comments on some of our argumentation and Heather M. Roxborough for her assistance with data coding and verification. Address correspondence to D. Voyer, Department of Psychology, University of New Brunswick, Bag Service \#45444, Fredericton, NB, E3B 6E4 Canada (e-mail: voyer@unb.ca).

\section{REFERENCES}

References marked with an asterisk indicate studies included in the meta-analysis.

*Alexander, G. M. (2005). Memory for face locations: Emotional processing alters spatial abilities. Evolution \& Human Behavior, 26, 352-362.

*Alexander, G. M., Packard, M. G., \& Peterson, B. S. (2002). Sex and spatial position effects on object location memory following intentional learning of object identity. Neuropsychologia, 40, 1516-1522.

*BARNFIEld, A. M. (1999). Development of sex differences in spatial memory. Perceptual \& Motor Skills, 89, 339-350.

BENBow, C. P. (1988). Sex differences in mathematical reasoning ability in intellectually talented adolescents: Their nature, effects, and possible causes. Behavioral \& Brain Sciences, 11, 169-232.

Buller, D. J. (2005). Adapting minds. Cambridge, MA: MIT Press.

${ }^{*}$ Cattaneo, Z., Postma, A., \& Vecchi, T. (2006). Gender differences in memory for object and word locations. Quarterly Journal of Experimental Psychology, 59, 904-919.

${ }^{*}$ Cherney, I. D., \& Ryalls, B. O. (1999). Gender-linked differences in the incidental memory of children and adults. Journal of Experimental Child Psychology, 72, 305-328.

${ }^{*}$ Choi, J., \& L'HirondelLe, N. (2005). Object location memory: A direct test of the verbal memory hypothesis. Learning \& Individual Difference, 15, 237-245.

${ }^{*}$ Choi, J., \& Silverman, I. (2003). Process underlying sex differences in route-learning strategies in children and adolescents. Personality \& Individual Differences, 34, 1153-1166.

COHEN, J. (1977). Statistical power analysis for the behavioral sciences (2nd ed.). New York: Academic Press.

Cornell, D. G. (1997). Post hoc explanation is not prediction. American Psychologist, 52, 1380.

${ }^{*}$ Crook, T. H., Youngjohn, J. R., \& Larrabee, G. J. (1990). The misplaced object test: A measure of everyday visual memory. Journal of Clinical \& Experimental Neuropsychology, 12, 819-833.

*Dabbs, J. M., Chang, E.-L., Strong, R. A., \& Milun, R. (1998). Spatial ability, navigation strategy, and geographic knowledge among men and women. Evolution \& Human Behavior, 19, 89-98.

*Duff, S. J., \& Hampson, E. (2001). A sex difference on a novel spatial working memory task in humans. Brain \& Cognition, 47, 470-493.

${ }^{*}$ Eals, M., \& Silverman, I. (1994). The hunter-gatherer theory of spatial sex differences: Proximate factors mediating the female advantage in recall of object arrays. Ethology \& Sociobiology, 15, 95-105.

*ECuyer-Dab, I., \& Robert, N. (2004). Spatial ability and home range size: Examining the relationship in Western men and women. Journal of Comparative Psychology, 118, 217-231.

*Epting, L. K., \& Overman, W. H. (1998). Sex-sensitive tasks in men and women: A search for performance fluctuations across the menstrual cycle. Behavioral Neuroscience, 112, 1304-1317. 
Furlong, N., Lovelace, E., \& Lovelace, K. (2000). Research methods and statistics: An integrated approach. Fort Worth, TX: Harcourt.

Gaulin, S. J. C., \& FitzGerald, R. W. (1986). Sex differences in spatial ability: An evolutionary hypothesis and test. American Naturalist, 127, 74-88.

Gaulin, S. J. C., \& Fitzgerald, R. W. (1989). Sexual selection for spatial-learning ability. Animal Behaviour, 37, 322-331.

*Gaulin, S. J. C., Silverman, I., Phillips, K., \& Reiber, C. (1997). Activational hormonal influences on abilities and attitudes: Implications for evolutionary theory. Evolution \& Cognition, 3, 191-199.

Goldstein, D., Haldane, D., \& Mitchell, C. (1990). Sex differences in visual-spatial ability: The role of performance factors. Memory \& Cognition, 18, 546-550.

Guillem, F., \& Mograss, M. (2005). Gender differences in memory processing: Evidence from event-related potentials to faces. Brain \& Cognition, 57, 84-92.

Hedges, L. V., \& BecKer, B. J. (1986). Statistical methods in the metaanalysis of research on gender differences. In J. Hyde \& M. C. Linn (Eds.), The psychology of gender: Advances through meta-analysis. Baltimore: Johns Hopkins University Press.

Hedges, L. V., \& Nowell, A. (1995). Sex differences in mental test scores, variability, and numbers of high-scoring individuals. Science, 269, $41-45$.

Hellige, J. B., Bloch, M. I., Cowin, E. L., Eng, T. L., Eviatar, Z., \& SERGENT, V. (1994). Individual variation in hemispheric asymmetry: Multitask study of effects related to handedness and sex. Journal of Experimental Psychology General, 123, 235-256.

Hellige, J. B., \& Michimata, C. (1989). Categorization versus distance: Hemispheric differences for processing spatial information. Memory \& Cognition, 17, 770-776.

*Hill, R. D., Grut, M., Wahlin, A., Herlitz, A., Winblad, B., \& BäCKMAN, L. (1995). Predicting memory performance in optimally healthy very old adults. Journal of Mental Health \& Aging, 1, 57-67.

Horgan, T. G., Schmid Mast, M., Hall, J. A., \& Carter, J. D. (2004). Gender differences in memory for the appearance of others. Personality \& Social Psychology Bulletin, 30, 185-196.

Hyde, J. S., Fennema, E., \& Lamon, S. J. (1990). Gender differences in mathematics performance: A meta-analysis. Psychological Bulletin, 107, 139-155

HydE, J. S., \& LinN, M. C. (1988). Gender differences in verbal ability: A meta-analysis. Psychological Bulletin, 104, 53-69.

*Iachini, T., Sergi, I., Gennaro, R., \& Gnisci, A. (2005). Gender differences in object location memory in a real three-dimensional environment. Brain \& Cognition, 59, 52-59.

JAGER, G., \& Postma, A. (2003). On the hemispheric specialization for categorical and coordinate spatial relations: A review of the current evidence. Neuropsychologia, 41, 504-515.

*James, T. W., \& KimuRa, D. (1997). Sex differences in remembering the locations of objects in an array: Location-shifts versus locationexchanges. Evolution \& Human Behavior, 18, 155-163.

*Janowsky, J. S., Chavez, B., Zamboni, B. D., \& Orwoll, E. (1998). The cognitive neuropsychology of sex hormones in men and women. Developmental Neuropsychology, 14, 421-440.

Jones, C. M., Braithwaite, V. A., \& Healey, S. D. (2003). The evolution of sex differences in spatial ability. Behavioral Neuroscience, $117,403-411$

Kail, R., Carter, P., \& Pellegrino, J. W. (1979). The locus of sex differences in spatial ability. Perception \& Psychophysics, 26, 182-186.

Ketelaar, T., \& Ellis, B. J. (2000). Are evolutionary explanations unfalsifiable? Evolutionary psychology and the Lakatosian philosophy of science. Psychological Inquiry, 11, 1-21.

Kosslyn, S. M., Koenig, O., Barrett, A., Cave, C. B., Tang, J., \& GabRIELI, J. D. E. (1989). Evidence for two types of spatial representations: Hemispheric specialization for categorical and coordinate relations. Journal of Experimental Psychology: Human Perception \& Performance, 15, 723-735.

*Levy, L. J., Astur, R. S., \& Frick, K. M. (2005). Men and women differ in object memory but not performance of a virtual radial maze. Behavioral Neuroscience, 119, 853-862.

*Lewin, C., Wolgers, G., \& Herlitz, A. (2001). Sex differences favoring women in verbal but not in visuospatial episodic memory. Neuropsychology, 15, 165-173.

LEWONTIN, R. (1998). The evolution of cognition: Questions we will never answer. In D. Scarborough \& S. Sternberg (Eds.), An invitation to cognitive science: Vol. 4. Methods, models, and conceptual issues (pp. 107-132). Cambridge, MA: MIT Press.

LinN, M. C., \& Petersen, A. C. (1985). Emergence and characterization of sex differences in spatial abilities: A meta-analysis. Child Development, 56, 1479-1498.

LOCKHART, R. S. (2000). Methods of memory research. In E. Tulving \& F. I. M. Craik (Eds.), The Oxford handbook of memory (pp. 45-58). New York: Oxford University Press.

MaCCOBY, E. E., \& JACKLIN, C. N. (1974). The psychology of sex differences. Stanford, CA: Stanford University Press.

Marín-Martínez, F., \& Sánchez-Meca, J. (1999). Averaging dependent effect sizes in meta-analysis: A cautionary note about procedures. Spanish Journal of Psychology, 2, 32-38.

Masters, M. S. (1998). The gender difference on the Mental Rotations Test is not due to performance factors. Memory \& Cognition, 26, 444-448.

*McBurney, D. H., Gaulin, S. J. C., Devineni, T., \& Adams, C. (1997). Superior spatial memory in women: Stronger evidence for the gathering hypothesis. Evolution \& Human Behavior, 18, 165-174.

*Montello, D. R., Lovelace, K. L., Golledge, R. G., \& Self, C. M. (1999). Sex-related differences and similarities in geographic and environmental spatial abilities. Annals of the Association of American Geographers, 89, 515-534.

Piaget, J. (1952). The origins of intelligence in children. New York: International Universities Press.

'Postma, A., Izendoorn, R., \& De Haan, E. H. F. (1998). Sex differences in object location memory. Brain \& Cognition, 36, 334-345.

"Postma, A., Jager, G., Kessels, R. P. C., Koppeschaar, H. P. F., \& van HonK, J. (2004). Sex differences for selective forms of spatial memory. Brain \& Cognition, 54, 24-34.

*Postma, A., Winkel, J., Tuiten, A., \& van Honk, J. (1999). Sex differences and menstrual cycle effects in human spatial memory. Psychoneuroendocrinology, 24, 175-192.

"Rahman, Q., Abrahams, S., \& Jussab, F. (2005). Sex differences in a human analogue of the Radial Arm Maze: The "17-Box Maze Test." Brain \& Cognition, 58, 312-317.

*Rahman, Q., Wilson, G. D., \& Abrahams, S. (2003). Sexual orientation related differences in spatial memory. Journal of the International Neuropsychological Society, 9, 376-383.

*Robert, M., \& EcuYer-DaB, I. (2000, November). Do women excel in remembering the locations of both stationary and repositioned objects? Report presented at the 41st Annual Meeting of the Psychonomic Society, New Orleans, LA

'Robert, M., \& Savoie, N. (2006). Are there gender differences in verbal and visuospatial working-memory resources? European Journal of Cognitive Psychology, 18, 378-397.

Rosenthal, R. (1979). The "file drawer problem" and tolerance for null results. Psychological Bulletin, 86, 638-641.

Rosenthal, R. (1991). Meta-analytic procedures for social research (rev. ed.). Beverly Hills, CA: Sage.

Rosenthal, R., \& Rubin, D. B. (1986). Meta-analytic procedures for combining studies with multiple effect sizes. Psychological Bulletin, 99, 400-406.

Rybash, J. M., \& Hoyer, W. J. (1992). Hemispheric specialization for categorical and coordinate spatial representations: A reappraisal. Memory \& Cognition, 20, 271-276.

Sharps, M. J., \& Gollin, E. S. (1987). Memory for object locations in young and elderly adults. Journal of Gerontology, 42, 336-341.

*Sharps, M. J., Welton, A. L., \& Price, J. L. (1993). Gender and task in the determination of spatial cognitive performance. Psychology of Women Quarterly, 17, 71-83.

Sherry, D. F., Jacobs, L. F., \& Gaulin, S. J. [C.] (1992). Spatial memory and adaptive specialization of the hippocampus. Trends in Neurosciences, 15, 298-303.

*Silverman, I., \& Eals, M. (1992). Sex differences in spatial abilities: Evolutionary theory and data. In J. Barkow, I. Cosmides, \& J. Tooby (Eds.), The adapted mind: Evolutionary psychology and the generation of culture (pp. 533-549). New York: Oxford University Press.

Singleton, C. H. (1986). Sex roles in cognition. In D. J. Hargreaves \& A. M. Colley (Eds.), The psychology of sex roles (pp. 60-91). London: Harper \& Row.

*Tottenham, L. S., Saucier, D., Elias, L., \& Gutwin, C. (2003). Fe- 
male advantage for spatial location memory in both static and dynamic environments. Brain \& Cognition, 53, 381-383.

*van der Gaag, H., Langeveld, D., SijbrandiJ, K., \& van Haren, A. (2003). The influence of hormones on sex differences regarding spatial abilities. Unpublished manuscript, Utrecht University, Utrecht, The Netherlands.

*VeCCHI, T., \& GirelLI, L. (1998). Gender differences in visuo-spatial processing: The importance of distinguishing between passive storage and active manipulation. Acta Psychologica, 99, 1-16.

*Voyer, D., Imperato-McGinley, J., Brake, B., \& Roxborough, H. M. (2005). [Object location memory under implicit and explicit memory instructions]. Unpublished raw data.

Voyer, D., Rodgers, M. A., \& McCormick, P. A. (2004). Timing conditions and magnitude of gender differences on the Mental Rotations Test. Memory \& Cognition, 32, 72-82.
Voyer, D., \& SAunders, K. A. (2004). Examination of possible outcomes on the Mental Rotations Test: A factor analysis. Acta Psychologica, 117, 79-94.

Voyer, D., Voyer, S., \& Bryden, M. P. (1995). Magnitude of sex differences in spatial abilities: A meta-analysis and consideration of critical variables. Psychological Bulletin, 117, 250-270.

*West, R. L., Welch, D. C., \& Knabb, D. (2002). Gender and aging: Spatial-efficacy and location recall. Basic \& Applied Social Psychology, 24, 71-80.

WoLf, F. M. (1986). Meta-analysis: Quantitative methods for research synthesis. Newbury Park, CA: Sage.

(Manuscript received January 30, 2006; revision accepted for publication June 3, 2006.) 